\title{
The South African Transition to a Greener Economy through Small-to-Medium Sized Enterprise (SME) Integration into the Energy Mix for Economic Development
}

\author{
Sindile Dlamini (PhD Candidate) \\ The University of Westminster (United Kingdom)
}

\begin{abstract}
This study investigates the institutional environment of South Africa and its role as a barrier or enabler for small-to-medium-sized (SMEs) that operate within the green economy. The focus of the investigation is on the energy sector and entrepreneurs' experience in the government's procurement processes and the national regulatory framework overseen by the Department of Energy and Mineral Resources. Entrepreneurs and SMEs that enter procurement bids to generate electricity are faced with a highly complex and uncertain environment. The size of the investments required to successfully get an energy business up and running are enormous and very few have managed to do this successfully. Through a series of in-depth interviews, a small sample of entrepreneurs that have set up IPP plants and who have been involved with tender and procurement bids shed light on how they overcame challenges within this environment that presented as barriers and through the use of the strategic orientation of entrepreneurial orientation (EO), were eventually able to exploit opportunities within this environment. A case study method was used in the undertaking of this research. The findings indicate that the role of the state is both a barrier and an enabler and the use of the dimensions of EO namely; autonomy, proactiveness, innovativeness, competitive aggressiveness and risk-taking provide the competitive edge for firms that are successful within this sector.
\end{abstract}

Keywords: Economic development, entrepreneurial orientation, institutions, entrepreneurship, small-to-medium sized enterprises (SMEs) 


\section{Introduction}

Entrepreneurs and SMEs that enter procurement bids to generate electricity are faced with a highly complex and uncertain environment. The sheer size of the investments required to successfully get an energy business up and running are enormous and very few have managed to do this successfully. At present, South Africa still operates a single-buyer model in procurement projects. In a typical single-buyer model, the IPP sells electricity to the singlebuyer (Eskom a state-owned enterprise) and the single-buyer sells the electricity to its customers. The electricity is sold to the buyer (i.e. the electricity changes ownership) at the point of connection to the transmission system. The electricity is transported across the distributors and ultimately to the end-use customers. There is no direct contractual relationship between the IPP and the end-use customers. The IPP pays chargers to the transmission company for the connection to the transmission system and for the use of the transmission system (Tusan, 2008). Therefore, the first assumption this paper makes is that entrepreneurs that operate within this space need higher levels of entrepreneurial orientation than many other sectors of the green economy. This is due to the fact that there is a sole customer for mass energy projects. Moreover, not only does Eskom act as the IPPs biggest ( sometimes only) customer but also acts as the greatest source of competition and has the ability to put a halt on IPP projects should they place a pause on calls for bids as was the case between 2014 and 2016. Thus, the state-owned enterprise acts as both a barrier and an enabler for IPP entrepreneurial projects. According to Rosenbuch et al. (2013), numerous scholars have argued that the external environment affects firm performance (Bain, 1956; Rumelt, 1991; Schmalensee, 1985), however, it has been a challenge to generate results on the environment-performance relationship. This study aims to investigate this notion within the unique context of South Africa's green economy especially the case of the energy sector. The relationship between the external environment and firm performance appears to be highly complex. Furthermore, the environment may not affect firm performance directly; rather it may stimulate firm-specific strategic behaviours that, in turn influence firm performance (Porter, 1980; Rosenbusch, Rauch, \& Bausch, 2013). This indicates that the exact means by which firms make use of opportunities and resources provided by the environment to enhance their performance remain unclear. Literature has made it implicit that firms need to acquire resources from their external environment and turn them into products and services, exploring and exploiting opportunities provided by the environment. Within this complex relationship, entrepreneurial orientation (EO) is a critical factor because it influences specific strategic decisions and resource allocations (Atuahene-Gima \& Ko, 2001) that favour opportunity exploration and exploitation (D. Miller, 1983). Only those firms that apply the appropriate strategic orientation in a specific environment may be able to transform advantages provided by the environment into above average performance levels. Various scholars have investigated whether EO is the missing link in the task environment- performance relationship and have endeavoured to develop meaningful theoretical mechanisms by which the environment affects firm performance via EO (Rosenbusch, Brinkmann, \& Bausch, 2010; (Lumpkin \& Dess, 1996). Although, the results from these studies support the notion that EO is the missing link in the task environment-performance relationship within developed country environments. This relationship remains yet to be explored within the context of a developmental state. This paper aims to apply the dimensions of EO as they would relate to a 
developmental state; South Africa and specifically look at the energy sector of this country as it attempts to further the national and global agenda of transitioning toward a more sustainable world for all.

\subsection{Purpose}

The purpose of this paper is to investigate the relationship between the concepts of entrepreneurial orientation and managerial discretion within small-to medium sized enterprises (SMEs) within the unique institution context of South Africa. The focus is on SMEs contributing to a greener economy within South Africa's energy sector and the role that the institutional environment plays in the facilitation of the development of these firms. It also discusses the role of the institutional environment as a potential barrier or enabler to the growth of these firms.

\subsubsection{Methodology}

This study gained insights from a small group of entrepreneurs within the energy sector. Managers from a mix of IPPs and an energy trading company were interviewed about their experiences of establishing an energy business within South Africa. A semi-structured questionnaire was used to guide the discussions, but the participants were given the freedom to address anything they deemed to be pertinent to their own individual experiences. The sample consisted of 10 entrepreneurs and 3 institutional representatives who explained the regulatory framework and institutional perspective.

\section{Literature review}

According to Rosenbuch et al. (2013), numerous scholars have argued that the external environment affects firm performance (Bain, 1956; Rumelt, 1991; Schmalensee, 1985), however, it has been a challenge to generate results on the environment-performance relationship. This study aims to investigate this notion within the unique context of South Africa's green economy especially the case of the energy sector. The relationship between the external environment and firm performance appears to be highly complex. Furthermore, the environment may not affect firm performance directly; rather it may stimulate firm-specific strategic behaviours that, in turn influence firm performance (Porter, 1980; Rosenbusch, Rauch, \& Bausch, 2013). This indicates that the exact means by which firms make use of opportunities and resources provided by the environment to enhance their performance remain unclear. Literature has made it implicit that firms need to acquire resources from their external environment and turn them into products and services, exploring and exploiting opportunities provided by the environment. Within this complex relationship, entrepreneurial orientation (EO) is a critical factor because it influences specific strategic decisions and resource allocations (Atuahene-Gima \& Ko, 2001) that favour opportunity exploration and exploitation (D. Miller, 1983). Only those firms that apply the appropriate strategic orientation in a specific environment may be able to transform advantages provided by the environment into above average performance levels. Various scholars have investigated whether EO is the 
missing link in the task environment- performance relationship and have endeavoured to develop meaningful theoretical mechanisms by which the environment affects firm performance via EO (Rosenbusch, Brinkmann, \& Bausch, 2010; Lumpkin \& Dess, 1996). Although, the results from these studies support the notion that EO is the missing link in the task environment-performance relationship within developed country environments. This relationship remains yet to be explored within the context of a developmental state. This paper aims to apply the dimensions of EO as they would relate to a developmental state; South Africa and specifically look at the energy sector of this country as it attempts to further the national and global agenda of transitioning toward a more sustainable world for all.

\section{The role of formal and informal institutions in facilitating entrepreneurial}

\section{ventures that rely heavily on procurement}

Entrepreneurship and institutional theory literature (Shane, 2000; North, 1990; Scott, 2002) have discussed how entrepreneurs adopt different behaviours, such as manipulating or exploiting institutions (formal or informal) in their favour (Cacciolatti \& Lee, 2016) or establishing adaptive mechanisms of defence based on the exploitation and manipulation of institutions such as personal networks, trust or in some instances more or less legitimate actions (Aidis and Adachi, 2007) to sustain the livelihood of their business venture. Some operate in environments that have high levels of volatility and complexities which also means that there is an increased level of competitiveness among firms, as a consequence, entrepreneurs have to find ways to survive within the marketplace (Cacciolatti and Lee, 2016). To meet these challenges, entrepreneurs can be inclined to display certain strategic orientations. The introduction of the concept of entrepreneurial orientation (EO) by Lumpkin and Dess (1996) is one such example of a strategic orientation and defines EO as 'strategymaking processes and styles of firms that engage in entrepreneurial activities.' EO is a valuable factor because it influences specific strategic decisions and resource allocations (Atuahene-Gima \& Ko, 2001; Rosenbusch, Rauch, \& Bausch, 2013) that favour opportunity exploration and exploitation (Miller, 1983; Rosenbusch et al., 2013). Only those firms that apply the appropriate strategic orientation are said to achieve above average performance levels. Miao et. al (2017) specifically refer to EO as multidimensional construct describing the strategy-making process at the organisational level including dimensions such as innovation, proactiveness, and risk-taking behaviour (Covin \& Slevin, 1991; Miao, Coombs, Qian, \& Sirmon, 2017).

In their 1996 paper, Lumpkin and Dess conceptualised EO as a construct made of five main dimensions, namely autonomy, innovativeness, risk-taking, proactivity and competitive aggressiveness. Entrepreneurs can have different profiles or mixes of EO, and this affects the way they run their firms, the long-term aims for their business, the tactical choices relayed to the allocation of resources, and overall, the ethos followed in their business activity. Autonomy is defined as independent action by an individual or team aimed at bringing forth a business concept or vision and carrying it through to completion (Lumpkin et al., 2009). Lumpkin et al. (2009) state that autonomy is the driving force of entrepreneurial value creation describing this dimension as the independent spirit and freedom of action necessary to advance new venture development (Lumpkin, Cogliser, \& Schneider, 2009). For 
entrepreneurship to thrive in many organisational contexts, "the exercise of autonomy by strong leaders, unfettered teams, or creative individuals who are disengaged from organisational constraints" is required (Lumpkin \& Dess, 1996). Autonomy affords organisational members the freedom and flexibility to develop and enact entrepreneurial initiatives. In the context of strategic entrepreneurship, autonomy enables both opportunityseeking and advantage seeking behaviours (Ireland, Hitt, Sirmon, 2003).

Innovativeness refers to a willingness to support creativity and experimentation in introducing new products/ services, and novelty, technological leadership and R\&D in developing new processes (Cacciolatti \& Lee, 2016). Alternatively, some authors have made reference to this dimension as product innovation which represents firm's efforts to experiment with and develop new products designed to meet current or future market demands (Chirico, Sirmon, Sciascia \& Mazzola, 2011; Lumpkin \& Dess, 1996, 2001). In cases specific to small businesses where the decision-making is concentrated to the owner/ manager, innovativeness may translate into the innovativeness of the entrepreneur/ owner/ manager rather than the innovativeness of the firm (Hausman, 2005).

Risk-taking means a tendency to take bold actions such as venturing into unknown new markets, committing a large portion of resources to ventures with uncertain outcomes, and/or borrowing heavily (Cacciolatti \& Lee, 2016). The risk-taking dimension of EO can also be argued to have a positive mediating effect. Only by taking on the risks associated with exploration and exploitation activities can firms transform opportunities provided by the environment into competitive advantage and higher than average performance levels (Rosenbusch et al., 2013). Proactiveness is an opportunity-seeking, forward-looking perspective involving introducing new products or services ahead of the competition and acting in anticipation of future demand to create change and shape the environment (Rosenbusch et al., 2013). The rapid rate of change and difficulty in predicting future events require a high degree of proactivity. Proactiveness helps firms to explore and exploit new resources that are required, in turn, for the successful exploration and exploitation of new markets (Lumpkin and Dess, 2001). Competitive aggressiveness reflects the intensity of a firm's efforts to outperform industry rivals, characterised by a combative posture and a forceful response to competitor's actions (Cacciolatti \& Lee, 2016).

Although EO is a complex construct to measure the level of entrepreneurship in an entrepreneur, only some of its elements are recognised to influence decision-making. For the context of this study, decision-making is defined as assessments or judgements used by entrepreneurs during cognitive processes involving opportunity evaluation, venture creation and growth. (Mitchell, Mcdougall, Morse, \& Smith, 2002). For example, autonomy has been linked to having an effect on decision-making as it is essential to the effectiveness of processes of leveraging a firm's existing strengths, identifying opportunities by granting the entrepreneur/ manager independence of action, thus encouraging the development of new opportunities that are beyond the organisation's current capabilities as well as encouraging the development of new ventures and/or improved business practices (Kanter, North, Bernstein \& Williams, 1990; Lumpkin et al., 2009). Autonomy or independent entrepreneurial action provides the motivation needed to explore business opportunities, bringing forth the proposition of new business concepts, and carry them through to completion (Bird, 1988; 
McMullen \& Shepherd, 2006). Autonomy grants a wider scope within which the entrepreneur/ manager can make decisions. Decision-making by individuals or teams who are unhindered by strategic norms or organisational traditions that impede them is necessary to effectively investigate entrepreneurial possibilities and champion new venture concepts (Burgelman, 1983; Green, Bush, \& Hart, 1999).

The discussion thus far has highlighted the importance of managerial discretion to the independent action and decision-making processes of entrepreneurial ventures. Autonomy is integral to the independent action that can be exercised by an entrepreneur/ owner but it may be even more important in settings where strategic renewal occurs because of the key individuals that champion entrepreneurial initiatives that transform an organisation's strategic posture (Lumpkin et al., 2009). Managerial discretion can be likened to the judgement used by managers when deciding on a particular action. Autonomy can be linked to managerial discretion on the basis that it is the independence to act on or pursue certain decisions that have emerged from entrepreneurial cognitive processes. Although the role and importance of some types of autonomy have been studied in prior management research (e.g., Hackman \& Oldham, 1975; Hart, 1991), the effect of autonomy as a dimension of EO is still a developing body of literature and has mainly been focused on exploring the role that autonomy plays in entrepreneurial value creation (Lumpkin et al., 2009). However, the effect of autonomy on managerial discretion has been neglected in the literature.

4. The impact of decision making for entrepreneurs in a highly complex and competitive institutional environment

The decision-making process varies from one entrepreneur to another, and some have more discretion in the way they make choices because different entrepreneurs face different challenges, and some are more constraining than others. Under the assumption that EO affects decision making and that managerial discretion is part of decision making, it is not unlikely to assume that EO has an effect on managerial discretion. It is possible for one to make a few assumptions of how EO may affect managerial discretion. Firstly, the dimension of proactiveness keeps firms alert by exposing them to new technologies, making them aware of marketplace trends, and helping them evaluate new possibilities (Lumpkin et. al, 2009). This means that entrepreneurs have different magnitude of discretion in their decisions. Decisionmaking is part of managerial discretion. Managerial discretion is the latitude of action that is available to decision makers in a given situation (Hambrick \& Finkelstein, 1987). Managerial discretion can be described as the latitude of managerial action available to a decision maker (e.g., a top manager) in a given situation (Hambrick \& Finkelstein). Higher levels of discretion enable leaders with a wider range of options and greater latitude of action (Wangrow, Schepker, \& Barker , 2015). It is known that managerial discretion is useful in situations where managers have an organisational hierarchy consisting of a wide range within which to exercise decision making such as within a medium-to-large sized business but may not be so useful in situations where the scope of decisions is narrower such as within a smallsized firm. Arguably, if an entrepreneur makes all the decisions, the discussion about managerial discretion is irrelevant predominantly to a small-sized firm context as there is often no hierarchical structure with mangers to oversee various business functions as in a small-sized firm context the entrepreneur would be responsible for most of the functions in 
the business. However, this is not the case for SME firms within South Africa's context as many of these types of firms grow over time (expanding in terms of human capacity) but remain classified as SMEs and thus the relevance of the discourse of managerial discretion becomes pertinent.

\section{The role of managerial discretion in the procurement process of entrepreneurial ventures}

Managerial discretion is affected by various factors. In the development of the managerial discretion construct, Hambrick and Finkelstein (1987) focus on three forces that determine a manager's latitude of action: the task environment, internal organisational factors, and managerial characteristics. First, the task environment which is characterised by factors in the organisation's domain (e.g. industry) and how the organisation functions within its domain. Since the task environment alters managerial discretion, managers have substantially differing roles in affecting organisational performance across industries. The task environment is expected to positively influence managerial discretion when product or service characteristics vary greatly across industry competitors, the market for the industry's products or services is growing, and demand for the industry is highly concentrated, highly regulated, and powerful external forces, such as competitors, suppliers, and buyers, exist (Hambrick \& Finkelstein, 1987; Wangrow et al., 2015). Related to this, Dess and Beard (1984) introduced munificence, dynamism, and complexity as dimensions of the task environment relevant to industry firms. Many of the managerial discretion task environment factors closely resemble these three dimensions and it is reasonable to conclude that industry munificence, dynamism and complexity all potentially increase a manager's latitude of action (Wangrow et al., 2015).

Internal organisational factors influenced by powerful internal stakeholders and resource availability are the second force shaping discretion. The internal organisation defines the degree to which the organization is open to a variety of possible actions and subsequently empowers the CEO to execute those actions (Hambrick \& Finkelstein, 1987). Forces such as an organisation's size, age, and culture. Thus, a manager seeking to initiate change can be severely constrained by the ingrained culture of a larger or older organisation as a result of standardized routines or more formally defined roles and control systems. Relatedly, capital intensity and resource availability can also constrain or enable a manager's latitude of action. Organisations that have made tremendous capital outlays are likely to be highly committed to the current course of actions and potentially tied closely to their current products and processes (Hambrick \& Macmillan, 1985; Wangrow et al., 2015). The final force affecting managerial discretion is the managerial characteristics. Child (1997) made the argument that executives in the same environmental situation will set different levels of discretion for themselves based on their interpersonal linkage to the environment. A top manger's tolerance for ambiguity, locus of control and ability to deal with cognitive complexity compose the psychology-based personal characteristics in this force. Attributes of the top manager's relationship with the firm, including his of her power base and commitment to the status quo, are also included in defining personal characteristics affecting discretion (Wangrow et al., 2015).

Literature covers how EO can be utilised by firms that apply the appropriate strategic orientation in a specific environment and may be able to transform advantages provided by 
the environment into above-average performance levels (Rosenbusch et al., 2013). Despite the strong effect of EO on decision-making and on the importance of having discretion of making decisions (i.e. managerial discretion equates to the magnitude of decision power/ability). What remains unknown is whether EO per se may affect managerial discretion in some manner. At this point one may think that the effect of EO on managerial discretion is obvious, but so far this has been untested. The EO dimension of autonomy for example, affects decision making in such a way that the extent to which a manager is autonomous governs the latitude of action he/she may exercise in any given setting. Likewise, the EO dimension of risk-taking affects decision making, for example, an entrepreneur that exercises high levels of risk-taking may be inclined to test out a new product or technology and integrate it into the business. The added dimension of competitive aggressiveness may also prompt the entrepreneur to beat his/her competitors and be the first to market this new product or technology among customers. The following section of this paper discusses the findings of this study in relation to the use of EO and managerial discretion within energy SMEs in South Africa and how they navigate the institutional environment.

\section{Findings}

1. Ever changing legislation, reports that most changes were welcomed as made the process more simplified

From 2007 when the first national calls for bids were put out to present day, a number of significant changes have occurred. Partly due to the fact that this was a new process to deal with an urgent national problem. However, respondents to the study reported that each bidding round was like beginning a fresh round and the processes did not necessarily get simpler. Which presented the question as to why this was occurring because it is well known that the economy must transform and transition to cleaner energy, but the institutional support mechanisms and processes do not seem to be getting easier to facilitate such a transition. Furthermore, reports that some entrepreneurs felt like the 'goal post' kept moving and each bid round was like a new venture all over again, so much so that companies that have been in this space for more than 10 years and have turned revenues well into millions of Rands (ZAR) still consider themselves to be start-ups.

2. Although firms had been operating for over 10 years, they still view themselves as start-ups due to the how heavily reliant they are on the new IRP and thus new requirements are introduced bringing about the need to find larger and new investment sources

Financiers such as banks will only fund companies on the basis of having secured a power purchase agreement (PPA) with either Eskom or a municipality so that they can derisk the investment as much as possible. This has resulted on some SMEs trying for years to get financing from banks to no avail. However, once the announcement is made that the national government is looking to procure power in an upcoming period, banks look at companies more favourably depending on the feasibility of the financial model presented. 
3. Many entrepreneurs have failed when trying to start this kind of venture because the primary customer is Eskom and when Eskom does not need to procure energy from IPPs, banks and investors do not invest

This dynamic has caused significant challenges for many SMEs and many that were in the process of establishing themselves, having invested heavily in setting up businesses have found themselves at a loss as the regulatory framework has been a barrier to further advancing in the development of these business.

4. Securing PPAs with both Eskom and municipalities have proven to be very difficult for many energy SMEs but with the rising demand for electricity forecast for the future, this may change.

This will be an area that may see more opportunity in the near future and may open up more for smaller players to enter as the existing Eskom infrastructure is barely able to meet current electricity demand. Furthermore, the carbon conscious footprint of the national agenda will also see the country rely more on renewable energy sources in the future.

\section{The role of the Single Buyer Model}

The Single Buyer model has been a challenge for many SMEs. With the single-buyer model, the independent power producer (IPP) sells electricity to the single-buyer (Eskom a state-owned enterprise) and the single-buyer sells the electricity to its customers (Tusan, 2008). This has translated to Eskom acting as both a customer and a competitor at the same time (acting as both an enabler and a barrier at the same time). Currently, the framework is being revised to a "Willing Buyer- Willing Seller" model which will potentially create more opportunity of these firms.

6. Race has been seen as little to do with this type of venture but the core issue surrounding this is inequality (haves and have-nots) as this is a Billion Rand investment arena for each tender round, entrepreneurs with vast sums of wealth are most likely to succeed

Due to the unique context of South Africa with its post-apartheid legacy, it was necessary to discuss the implications of this and if this contributed to the awarding of tenders. It has been preliminarily established within the energy sector, race plays a small role in this but wealth and access to networks plays a greater role in the success rate of firms within this sector. However, this is still undergoing further investigation.

7. The entry of the big multinationals into these bids has made it even harder for smaller players to compete

The entry of big multinationals has also added an extra layer of complexity for smaller players as they do possess the capital required to set up IPPs quickly within minimal risk to them and a greater chance of winning power procurement bids. This has resulted in a higher failure rate for smaller SMEs who struggle to even acquire financing from banks and investors. 


\section{Conclusion}

This paper has discussed the roles played by the institutional environment of South Africa and the regulatory framework surrounding the operations of SMEs and entrepreneurs that have set up IPPs and have entered into procurement bids to aid in the meeting the electricity demands of South Africa. Utilising the case study method and a series of in-depth interviews with entrepreneurs who have participated in procurement bids, findings have uncovered that the role played by the state is both a barrier and an enabler to the development of these firms and that current regulatory framework places severe limitations to the growth of such firms, however this sector will open up with the revision of this framework,

\section{Acknowledgment (TNR 12pt. bold)}

This paper is an output of the PhD project entitled the barriers and enablers of the of SME innovation and entrepreneurial activity within South Africa's green economy. A special thanks is extended to Dr Luca Cacciolatti and Dr Ioannis Christodoulou from the University of Westminster for their guidance on the development of this research project.

\section{References}

Aidis R and Adachi Y. Russia: firm entry and survival barriers. Economic Systems. 2007; Vol. 31 (No.4): pp. 391-411.

Atuahene-Gima,K.,\& Ko,A. 2001. An empirical investigation of the effect of market orientation and entrepreneurship orientation alignment on product innovation. Organization Science, 1:54-74.

Bird, B. (1988). Implementing entrepreneurial ideas: The case for intention. Academy for Management Review, 13, 442-453.

Burgelman, R.A. (1983). A process model of internal corporate venturing in the diversified major firm. Administrative Science Quarterly, 28, 223-244.

Busenitz, L. W., \& Lau, C. M. 1996. A cross-cultural cognitive model of new venture creation. Entrepreneurship Theory and Practice, 20 (4): 25-39.

Busenitz, L. W., Gómez, C., \& Spencer, J. W. (2000). Country institutional profiles: Unlocking entrepreneurial phenomena. Academy of Management Journal, 43(5), 994-1003. https://doi.org/10.2307/1556423

Cacciolatti, L. \& Lee, S. H. (2016) Entrepreneurial marketing for SMEs. Palgrave MacMillian. ISBN: 978-1-137-53256-5. 
Covin, J.G., Green, K.M., \& Slevin, D.P. (2006). Strategic process effects on the entrepreneurial orientation-sales growth rate relationship. Entrepreneurship Theory and Practice, 30,57-81.

Crossland, C., \& Hambrick, D. C. (2011). Differences In Managerial Discretion Across Countries: How Nation-Level Institutions Affect The Degree To Which. 819(July 2009), 797-819. https://doi.org/10.1002/smj

Dess, G. G., \& Beard, D. W. 1984. Dimensions of organizational task environments. Administrative Science Quarterly, 29; 52-73.

Framework, U. N., Change, C., Africa, S., Indc, T., Agreement, P., Africa, S., ... Change, C. (1800). South Africa's Intended Nationally Determined Contribution ( INDC ) Introduction Context : National Priorities and Circumstances. 1-11.

Hackman, J.R. \& Oldham, G.R. (1975) Development of the job diagnostic survey. Journal of Applied Psychology, 60, 159-170.

Haleblain, J., \& Finkelstein, S. 1993. Top management team size, CEO dominace and firm performance: The moderating roles of environmental turbulance and discretion. Academy of Management Journal, 36: 844-863.

Hambrick, D. C., \& Finkelstein, S. 1987. Managerial discretion: A bridge between polar views of organizational outcomes. Research in Organisational Behavior, 9:369-406.

Hambrick, D. C., \& Finkelstein, S. 1987. Managerial discretion: A bridge between polar views of organizational outcomes. Research in Organisational Behaviour, 9:369-406.

Hart, S.L. (1992). An integrative framework for strategy-making processes. Academy of Management Review, 17, 327-351.

Hausman, A. (2005). Innovativeness among small businesses : Theory and propositions for future research. 34, 773-782. https://doi.org/10.1016/j.indmarman.2004.12.009

Helmke G, Levitsky S. 2004. Informal institutions and comparative politics: a research agenda. Perspectives on Politics 2: 725-740.

Ireland, R.D., Hitt, M.A., \& Sirmon, D.G. (2003). A model of strategic entrepreneurship: The construct and its dimensions. Journal of Management, 29, 963-989.

Kanter, R.M., North, J., Bernstein, A.P., \& Williams, A. (1990). Engines of progress: Designing and running entrepreneurial vehicles in established companies. Journal of Business Venturing, 5, 415-430.

Knight, G. A. 1997. Cross-cultural reliablity and validity of a scale to measure entrepreneruial. Academy of Management Best Paper Proceedings: 180-189.

Lumpkin, G. T., Cogliser, C. C., \& Schneider, D. R. (2009). E T \& P Understanding and Measuring Autonomy: (806), 47-69.

Magnan, M. L., \& St. Onge, S. 1997. Bank performance and executive compensation: A managerial discretion perspective. Strategic Management Journal, 18: 573-581. 


\section{$4^{\text {th }}$ International Conference on BUSINESS, MANAGEMENT \& ECONOMICS}

15 - 17 DECEMBER 2020

BERLIN, GERMANY

Miao, C., Coombs, J. E., Qian, S., \& Sirmon, D. G. (2017). The mediating role of entrepreneurial orientation: A meta-analysis of resource orchestration and cultural contingencies. Journal of Business Research, 77, 68-80. https://doi.org/10.1016/j.jbusres.2017.03.016

Mitchell, R. K., Mcdougall, P. P., Morse, E. A., \& Smith, J. B. (2002). E T \& P Cognition : Rethinking. 93-104.

North DC. 1990. Institutions, Institutional Change and Economic Performance. Cambridge University Press: New York.

North DC. Institutions, Institutional change and economic performance. Cambridge: Cambridge University Press; 1990.

Rosenbusch, N., Rauch, A., \& Bausch, A. (2013). The Mediating Role of Entrepreneurial Orientation in the Task Environment - Performance Relationship : A Meta-Analysis. 39(3), 633-659. https://doi.org/10.1177/0149206311425612

Scott WR. Institutions and Organisations. Thousand Oaks, CA: Sage; 2002.

Shane S. Prior knowledge and the discovery of entrepreneurial opportunities. Organization Science. 2000; 11(4): pp. 217-26.

Tuson, P., \& Power, P. B. (2008). Willing-seller / willing-buyer in a single buyer model. (September 2007), 2007-2009.

Walsh, J. 1995. Managerial and organizational cognition: Notes from a trip down memory lane. Organization Science, 6: 280-321.

Wangrow, D. B., Schepker, D., \& Barker Iii, V. L. (2015). Managerial Discretion : An Empirical Review and Focus on Future Research Directions. 41(1). https://doi.org/10.1177/0149206314554214

Wangrow, D. B., Schepker, D., \& Barker Iii, V. L. (2015). Managerial Discretion: An Empirical Review and Focus on Future Research Directions. 41(1). https://doi.org/10.1177/0149206314554214 